\title{
$X$. Inquiries in the elements of phonetics
}

\section{C.B. Cayley}

To cite this article: C.B. Cayley $(1846) \mathrm{X}$. Inquiries in the elements of phonetics, Philosophical Magazine Series 3, 28:184, 47-48, DOI: 10.1080/14786444608645351

To link to this article: http://dx.doi.org/10.1080/14786444608645351

曲 Published online: 30 Apr 2009.

Submit your article to this journal $2 \pi$

Џ Article views: 2

Q View related articles $₫$ 


\section{[ 47 ]}

$\mathrm{X}$. Inquiries in the Elements of Phonetics*.

By C. B. Cayley, Fellow of Trinity College, Cambridge.

To the Editors of the Philosophical Magazine and Journal.

Gentlemen,

SCHEME of Consonants. - Liquid Aspirates.-I start with $S$ that scheme which has the authority of Messrs. Latham and Whewell (waiving some undecided points), to which I would make a few additions. I denote, for convenience, the aspirates (so called perhaps fitly, as the breathing is more heard in them) universally by adding to the corresponding non-aspirates a small $h$, which thus becomes a symbol from a letter, and I make $J$, suitably to its form and origin, stand for German $J$, English $Y$.

\begin{tabular}{|c|c|}
\hline $\begin{array}{l}\text { Sharp. } \\
\text { P Ph } \\
\text { T Th } \\
\text { K Kh }\end{array}$ & $\begin{array}{l}\text { Flat. } \\
\text { B Bh } \\
\text { D Dh } \\
\text { G Gh }\end{array}$ \\
\hline
\end{tabular}

1 observe that the flat consonants appear formed from the sharp by an effort (to make their sound stronger and more continuous), which also, being repeated, converts the flat into the liquid. This effort has not prevented, in the flat order, the introduction of the second force of aspiration as in the sharp: hence there is some reason to conjecture that the liquids might be susceptible of this force. In short, the symmetry of the system requires an order of liquid aspirates, which might be written $M h, N h, L h, R h$. May we not identify $M h$ with French $m$ or $n$ nasal, $N h$ with English $N g, L h$ with Welsh $L l, R h$ with Arabic Ghain?

Concerning the latter two, my chief difficnlty is to know whether they are simple or compound sounds; but

The Welsh $L l$ is stated in Davis's Grammar to be the aspirate of $L$, pronounced by pressing the tongue against the teeth on both sides with a forcible emission of breath.

The Arabic Ghain is described by De Sacy as a sound resembling $R$ and $G$, " comme l'R graissayé des Provencaux:" We often hear imperfect pronunciations of $R$ which might give the idea of this secondary liquid.

But I shall chiefly insist on $M h$ or $m$ nasal, because it coincides witl $F$ and $V$, the aspirates as $M$ with $B, N$ with $D$, \&c. Cotuptre the pronunciation of combattre, entendre, enfant, envahir; likewise it has the same resemblance to the dental $N$, which $P h, B h$ being formed by the teeth in part have to $T h$ (whenee the confusion made by children in those sounds, and

* From letters addressed to Mr. Latham. 
the Russian corruptions Feodor, Marpha, \&c. for Theodore, Martha), so that all the labial aspirates would approximate to dentals, and on this principle might it be that the liquid aspirate $N h$ approaches the next order of gutturals.

Should this paper be admitted, I shall hereafter consider some objections that have been communicated to me, and proceed to an attempted analysis of vowel sounds.

C. B. Cayley.

XI. On Fresnel's Theory of Double Refraction. By Archibald Sмith.

To the Edilors of the Philosophical Magazine and Journal. Gentlemen,

$\mathrm{T}$ an article on Fresnel's Theory of Double Refraction, in 1 the Supplement to the December Number of the Philosophical Magazine, Mr. Moon has quoted part of an article of mine in the first volume of the Cambridge Mathematical Journal, in which the following passage oceurs:- "Let the particle receive a small displacement, the projections of which on the co-ordinate axes are $\delta x, \delta y, \delta z$. Then supposing the displacement to be very small, the force of restitution may be taken as proportional to it, so that we have," \&c. I am not surprised that $\mathrm{Mr}$. Moon should remark on this passage, "what is meant by the mysterious principle 'supposing the displacement to be very small, the force of restitution may be taken as proportional to it,' I profess myself unable to understand."

The clause in italics, which was added to my manuscript when it was sent to the press, to remove, I believe, what was thought an abruptness in the reasoning, is certainly incorrect when applied to a doubly refracting medium. What was intended to be expressed, no doubt, was, that in the case supposed terms involving powers of $\delta x, \delta y, \delta z$ higher than the first might be neglected. But this expression is only equivalent to the other in the case of a singly refracting medium. I may mention that in the middle of page 7 of the article in the Cambridge Mathematical Journal, the word "rays" was, by a mistake, substituted for "waves." These mistakes are corrected in the second edition of the first volume of the Cambridge Mathematical Journal which is now printing. As they have been noticed in your Journal, I shall feel much obliged by your inserting this explanation when you can afford space for it.

Your obedient Servant,

25 Old Square, Lincoln's Inn, Dec. 20. Archibald SMIth. 